\title{
UNDESCENDED TESTIS: A STUDY OF 50 CASES
}

\author{
Lt Col KJ PHILIPOSE vSM Bar ${ }^{*}$, Col KK MAUDAR ${ }^{+}$, \\ Maj SAMIR GUPTA \\ (Department of Surgery. Armed Forces Medical College, Pune)
}

\begin{abstract}
Fifty consecutive cases of undescended testis treated at a service hospital over a period of 3 years from January 1993 to December 1995 were studied. Only 2 patients (4\%) were below the age of 2 years and $25(50 \%)$ were past the age of 15 years. Two cases presented with seminoma in intraobdominal testis. Ultrasonography was found unreliable in localizing the impalpable testis. Subdartos pouch orchiopexy (Winsburry-White) was the definitive procedure adopted in $\mathbf{2 1}$ out of the 25 orchiopexies performed and the results were good. Orchidectomy seems the best option of treatment in post-pubertal patients with unilateral symptomatic maldescent.
\end{abstract}

MJAFI 1997; 53 : 107-110

KEYWORDS : Cryptorchism; Testis; Orchiopexy; Orchidectomy; Testis undescended.

\section{Introduction}

$\mathbf{U}$ ndescended testis occur in 0.8 per cent of 1 -year-old boys and thus represents the most common disorder of male sexual differentiation [1]. Early detection of the undescended testis and its placement in the scrotum is important as degenerative histologic changes can be demonstrated in these testis by 1.5 to 2 years. But it is a pity that many of these patients discover the absence of testis only at adolescence and by this time the testis is irreversibly damaged. The cause of testicular maldescent has been the subject of much conjecture and investigation but has not been precisely elucidated. In 1762 John Hunter concluded that "it is not easy to ascertain the cause of failure of descent but I am inclined to suspect that the fault originates in the testes themselves" [2]. Some 235 years later it is still difficult to ascertain the cause.

The problem of testicular non-descent is important because of the associated complications. The complications include decrease in fertility, malignant change, liability to trauma and torsion and associated hernias. Equally important is the psychological stress in the child and parents caused by an empty scrotum.

The majority of undescended testes $(80 \%)$ are palpable below the external inguinal ring and are easily managed by orchiopexy through a conventional 'groin and scrotal' approach. Some 20 per cent of undescended testes are impalpable and the localization and transfer of these high testes has been a challenge to the surgeon, paediatrician and endocrinologist alike [3]. A surprising paucity of studies in the Indian context exists on this common disorder. We report our experience during the management of 50 cases of undescended testis.

\section{Material and Methods}

This prospective study consisted of 50 consecutive cases of testicular non-descent treated in a service hospital during the period 01 January 1993 to 31 December 1995. All patients were admitted and the clinical presentation, the position of the testis, the surgical procedure undertaken and the results were evaluated. The role of ultrasonography in the preoperative localization of the undescended testis was studied by correlating with operative findings. Preoperative semen analysis was done in all adults. Orchidectomy specimens were subjected to histopathological studies.

\section{Results}

Age at presentation is given in Table 1. Majority of patients $(50 \%)$ in this study presented after

Reader, ${ }^{+}$Professor and Head, "PG Student, Department of Surgery, Armed Forces Medical College, Pune - 411040. 
the age of 15 . Only 2 patients (4\%) were brought before the age of 2 years which is the currently accepted target period during which orchiopexy is to be undertaken to get optimum results.

TABLE 1

Age at presentation in 50 patients with undescended testis

\begin{tabular}{lr}
\hline Age (years) & No of patients \\
\hline $1-2$ & $2(4 \%)$ \\
$2-5$ & $5(10 \%)$ \\
$5-10$ & $13(26 \%)$ \\
$10-15$ & $5(10 \%)$ \\
$15-45$ & $25(50 \%)$ \\
\hline
\end{tabular}

In 40 per cent of patients the undescended testis escaped parental detection (Table 2). In 10 per cent patients, the absence of testis was detected only when one of the complications developed or when the patients were medically examined for recruitment in the armed forces.

TABLE 2

Mode of presentation in $\mathbf{5 0}$ patients with undescended testis

\begin{tabular}{lc}
\hline Presenting compliants & No. of patients \\
\hline Absence of testis noticed by parents & $22(44 \%)$ \\
Noticed by patient himself & $20(40 \%)$ \\
Infertility & $2(4 \%)$ \\
Tumour & $2(4 \%)$ \\
Torsion & $1(2 \%)$ \\
Hernia & $3(6 \%)$ \\
\hline
\end{tabular}

The non-descent was more common on the right side being present in 27 (54\%) patients, while 17 had a left-sided anomaly. The defect was bilateral in 6 patients (12\%).

The testis could be palpated in 39 patients (78\%) only. Position of the testis on clinical examination and ultrasonography are given on Table 3. On clinical examination 10 patients $(20 \%)$ were discovered to have a hemia. However, on surgical exploration the processes vaginalis was found patent in 44 patients (88\%).

Two patients in this series presented with lower abdominal lumps which were found to be seminomas. Both were adults ( 20 years and 22 years of age). One had an unilateral right sided non-descent
TABLE 3

Clinical and ultrasonograph position of the testis in $50 \mathrm{pa}-$ tients with undescended testis

\begin{tabular}{lcc}
\hline Position of testis & $\begin{array}{c}\text { On clinical } \\
\text { examinattion }\end{array}$ & $\begin{array}{c}\text { On ultrasound } \\
\text { examinattion }\end{array}$ \\
\hline Abdominal & 4 & - \\
Canalicular & 39 & 20 \\
High scrotal & 6 & 6 \\
Ectopic & 1 & - \\
Inconclusive & - & 22 \\
\hline
\end{tabular}

(*Two cases of testicular tumour in intra-abdominal testis excluded)

and the other had bilateral non-descent.

Detalis of surgical procedures undertaken in this study are given in Table 4 . Out of the 49 patients who underwent surgery, orchiopexy was done in 25 patients and the remaining 24 underwent orchiectomy. One patient had successful resection of testicular tumour. The other patient with bilateral undescended testes and right sided tumour refused surgery and was lost to follow-up.

TABLE 4

Type of surgery

\begin{tabular}{lrl}
\hline Type of surgery & $\begin{array}{c}\text { No. of patients } \\
(n=49)\end{array}$ \\
\hline Orchiopexy & 25 & $(50 \%)$ \\
Dartos pouch & 21 & $(42 \%)$ \\
Keetly Torek & 2 & $(4 \%)$ \\
Suture fixation to scrotum & 2 & $(4 \%)$ \\
Orchidectomy & 24 & $(48 \%)$ \\
Resection of testicular tumour & 1 & $(2 \%)$ \\
\hline
\end{tabular}

\section{Discussion}

The child with testicular non-descent is a common referral to the surgical out-patient department [3]. In this study half of the patients presented around or after puberty and surprisingly in about 40 per cent of cases, this easily detectable malady escaped parental attention. This is in contrast to the reports in the Western literature. Seddon et al i4] found the mean age at diagnosis to be 7.5 years. Lowe et al [5] found a mean age of 3.9 years in patients with undescended testis in a paediatric surgical centre. This could be due to the 
fact that in the West, hospital deliveries are the normal practice and majority of these cases are detected by the paediatrician. In our country very few children have access to regular medical check ups.

In this series there is a high orchiectomy rate $(49 \%)$ due to the patients reporting late for treatment. Elder [6] recommends that orchiectomy should be done for post-pubertal males with unilateral non-descent or post-pubertal males with bilateral non-descent who have had a unilateral orchiopexy earlier. It is also recommended for complications like malignancy and torsion with gangrene. All the orchiectomy specimens were subjected to histopathological examination which confirmed testicular atrophy with small seminiferous tubules, few spermatogonia and more peritubular tissue and fibrosis. Lipshulz et al [7] have shown that orchiopexy after the age of 2 years does not result in any change in subsequent fertility. Grass et al [8] found that in post-pubertal patients orchiopexy yielded poor results with 83.5 per cent patients being azoospermic or oligospermic following surgery. In this study 2 patients with infertility and oligospermia were treated by orchiopexy without any improvement in sperm count at 2 years of follow-up.

About 20 per cent of undescended testes are impalpable [3]. Localization of these testes is a challenging problem. Madrozo et al [9] found ultrasound scanning (USS) useful in locating the testis only if it is located in the inguinal canal. Wolverson et al [10] also found USS useful in locating impalpable inguinal testes. In contrast Weiss et al [11] found that sensitivity of USS to be poor with only 13 per cent detection in non-palpable testes. USS is even more unreliable in intra-abdominal testis due to obscuring of images by bowel gas. In the present series USS could localize the testis in 20 out of 39 intracanalicular testis. It could not detect the testes in any of the intra-abdominal locations. This shows the unreliability of USS in locating the testes. All the investigation modalities currently available for detection of the impalpable testes, with the possible exception of laparoscopy, are unreliable. Operative exploration is the ultimate definitive study [3].

Two patients in our series presented with ma- lignancy. Campbell [12] reported a 10 per cent incidence of tumours in undescended testes. The small number of cases in this series could explain this difference in figures. Batista et al [13] state that seminoma is the most common neoplasm of the maldescended testis. In this series both the cases with malignancy had seminoma of the testis.

Various techniques of mobilization of the testis have been described. However, majority of the testes can be mobilized through an inguinal approach. None of the patient in our series required any special mobilization technique. Of the various methods of fixing the testis in the scrotum, the dartos pouch technique [14] is the most popular. Twenty one of our patients had their testis placed in the dartos pouch. In as many as 10 per cent of orchiopexies a satisfactory scrotal position is not obtained postoperatively. Testicular retraction was observed in 8 per cent of our patients who underwent orchiopexy.

The best results of treatment of testicular nondescent is possible only if the children are treated early, preferably before the age of 2 years. Thorough examination of newborns in the hospitals, health education of 'dais' and health workers in the detection of this condition and medical checkup at the time of admission to schools could help to detect this condition early enough to avoid the tragedy of orchiectomy in a young boy.

\section{REFERENCES}

1. Scorer CG, Farringion GH. Congenital deformities of testis and epidedymis. New York: Appleton-Century 1972, Chapter 2.

2. Hunter J. Observations on the state of the testis in the foetus and on the hernia congenita. In: Hunter J, Medical Commentaries Part I. London: A Hamilton, 1762.

3. Bianchi A. The impalpable testis. Ann R Col Surg Engl 1995: 77: 3-6.

4. Seddon JM, Savory L, Scott-Connere. Cryptorchidism- the role of medical education in diagnosis. South Med J 1985; 78: 1201-4.

5. Lowe DH, Brock WA, Kaplan GW. Laparoscopy for localisation of non-plapable testis. J Urol 1984; 131: 728-9.

6. Elder JS. The undescended testis : Hormonal and Surgical management. Surg Clin North Am 1988; 68: 983-1002.

7. Lipshulz LI, Laminos-Torres R, Greenspan CS, et al. Testicular function after orchiopexy for unilaterally undescended testis. N Engl J Med 1976; 195: 15-8.

8. Grasso M, Buonaguidi A, Lamia C, et al. Postpubertal cryptorchidism. Review and evaluation of fertility. J Urol 
1991; 20: 126-7.

9. Madrazo BL, Klugo RC, Parks JA, et al. Ultrasonographic demonstration of the undescended testis. Radiology 1979; 123: 1814.

10. Welverson MK, Houttuin E, Heibarg E. Comparison of CT with high resolution USS in localization of the impalpable undescended testis. Radiology 1979; 133: 181-6.

11. Weiss RM, Carter AR, Rosenfield AT. High resolution real time ultrasonography in the localisation of the undescended testis. J Urol 1986; 135: 936-8.
12. Campbell HE. The incidence of malignant growth undescended testicle: A reply and re-evaluation J Urol 1959; 81: $563-4$.

13. Batista MA, Whitmore WF, Chu FC, et al. Cryptorchidism and testicular cancer. J Urol 1980; 124: 382-4.

14. Winsbury $C D$, White $M W$. The pouch technique in surgical correction of eryptorchidism in infants and children. Surgery $1967 ; 62: 67-9$. 